\title{
CONTRIBUIÇÃO DA NOVA SOCIOLOGIA ECONÔMICA PARA REPENSAR A ECONOMIA NO SENTIDO DO DESENVOLVIMENTO SUSTENTÁVEL
}

\section{RESUMO}

O artigo trata da eventual contribuição da nova sociologia econômica (NSE) para uma sociologia do desenvolvimento sustentável. Elaborada a partir do início dos anos 1980, a NSE busca dar conta da economia como totalidade social, o que já representa uma abertura ao desenvolvimento sustentável. Ademais, considerando a economia sob o prisma das instituições, das organizações, das redes e das formas de governança, ela reinscreve a economia no seio da sociedade. Isso seria trivial se essa concepção já fosse reconhecida por nossas sociedades e até mesmo por nossas disciplinas. Como nossa pesquisa documental é feita em duas etapas, tratamos na primeira parte do surgimento da NSE; na segunda parte, examinamos diversas abordagens que propõem uma reconstrução da economia como objeto sociológico. Em conclusão, nos perguntamos o que podemos apreender dessas abordagens, tendo em vista uma melhor compreensão do desenvolvimento sustentável.

\section{Benoît Lévesque}

ÉNAP - École Nationale d'Administration Publique

UQAM - Université du Québec à Montréal

\begin{abstract}
This article deals with the new economic sociology's (NES) occasional contribution to the sociology of sustainable development. Beginning in the 1980s, the NES proposes to understand the economy as a social totality, including the sustainable development approach. Moreover, by considering the economy from the perspective of institutions, organizations, networks and governance modes, this view once again places the economy at the heart of society, which would be a minor development if this conception were already acknowledged by our society and even by our disciplines. Our documental research is conducted in two stages. The first part discusses the emergence of NES. In the second part we examine various approaches that propose the reconstruction of the economy as a sociological subject. Finally, we raise questions regarding what is possible to apprehend from these approaches, looking for a better understanding of the sustainable development.
\end{abstract}

PALAVRAS-CHAVE Nova sociologia econômica, desenvolvimento sustentável, economia, sociologia francesa, institucionalistas. KEYWORDS New economic sociology, sustainable development, economy, French sociology, institutionalists. 


\section{UMA GRANDE TRANSFORMAÇÃO: RUMO A UM NOVO PARADIGMA}

Inicialmente, quatro hipóteses guiaram nossa pesquisa sobre a produção recente no campo da NSE. Nossa primeira hipótese sugere que a idéia de uma nova sociologia econômica procura diferenciar-se da antiga, não exatamente a dos "pais fundadores", mas aquela dos anos 1920-1970, ou seja, a do paradigma parsoniano "economia e sociedade" e a de uma sociologia mais especializada: sociologia do trabalho, sociologia industrial, sociologia da empresa, sociologia do desenvolvimento, etc. Deixando para os economistas os objetos centrais da economia, tais como o mercado e a moeda, a antiga sociologia econômica tratava exclusivamente do que se passava na origem das atividades econômicas (as condições do desenvolvimento) ou nos seus efeitos (as conseqüências sociais), confirmando assim a separação entre o econômico e o social. A NSE se diferencia igualmente da sociologia marxista ao reverter o determinismo econômico da sociedade em favor de uma determinação social da economia. Paradoxalmente, ela reconsidera outros clássicos (Weber, Durkheim, Simmel), a partir de sua tentativa de dar conta da economia como totalidade social. Essa releitura dos clássicos revela que estes últimos buscavam estabelecer explicitamente um contraponto à teoria econômica que se impunha naquela época por meio do marginalismo (Cusin e Benamousig, 2004; Gislain e Steiner, 1995; Swedberg, 1987).

Nossa segunda hipótese propõe que a NSE surge num contexto comparável àquele dos clássicos, isto é, um contexto de "grande transformação". O fim do século XIX foi marcado, entre outras coisas, pela afirmação do laissez-faire, o qual justifica uma economia política que se autoproclama ciência, uma internacionalização que toma a forma de imperialismo, uma organização científica do trabalho que engendra o desaparecimento de diversas profissões e uma desqualificação da massa trabalhadora. Naquele contexto, o sindicalismo e a economia social começam a se institucionalizar, ao passo que os partidos de trabalhadores se organizam em contraponto à afirmação do laissez-faire e às suas conseqüências. Já o fim do século XX é igualmente caracterizado por um período de crise seguido de mutações que se multiplicam para esboçar os contornos de uma grande transformação. Um período de "destruição criadora", segundo a expressão de Schumpeter, na qual o questionamento de Marx e de Keynes é acompanhado do desvelamento das economias administradas de tipo soviético e até mesmo socialdemocrata, tornando possível a proposta neoliberal de uma autoregulação pelo mercado. Paradoxalmente, "no momento em que o capitalismo conquistador parece se impor no campo econômico, a necessidade de intervenções sociais das quais ele pretende prescindir ganha uma amplitude jamais vista" (Draperi, 2000 , p. 7). Tudo se passa como se o neoliberalismo sem querer tivesse contribuído para a reabilitação da sociedade civil, sem eliminar no entanto a necessidade de instâncias governamentais de regulação.

A grande transformação em curso seria, assim, composta de diversos vetores que representam tanto ameaças como oportunidades para pensar de outra maneira o desenvolvimento econômico, inclusive no sentido de um desenvolvimento sustentável. O primeiro vetor seria o de uma dupla crítica, reportando-se ao fim dos anos 1960: uma "crítica social", que se queria corretiva do capitalismo industrial, e uma crítica artística, mais radical, cujas demandas de autonomia e de criatividade exigiam transformações mais amplas do sistema de produção e de consumo, crítica esta prolongada pelos ambientalistas (Boltanski e Chapiello, 1999). O segundo vetor é o de uma globalização associada estreitamente a uma espécie de "financeirização", que engendra a criação de riquezas e, ao mesmo tempo, o forte crescimento de desigualdades entre o Norte e o Sul, como também no seio de todas as sociedades. Todavia, a globalização revela igualmente novas interdependências, uma nova inter-relação entre o local e o global (Sousa Santos, 2001; Zimmerman, 2005), que abrem um espaço comum aos militantes antiglobalização e aos promotores de outra forma de globalização, por meio do encontro de experimentos socioeconômicos com demandas por novas regulações da economia mundial. O terceiro vetor é constituído pelas tecnologias de informação e comunicação (TIC) e, sobretudo, pela nova economia, cujos inputs provêm da esfera do conhecimento e do saber, colocando a ênfase na interdependência entre o econômico e o social. Assim, a qualidade das relações sociais se impõe no contexto de uma economia que se torna cada vez mais relacional (Gadrey, 1996). O quarto e último vetor é o do aumento dos riscos, até o ponto em que alguns autores não hesitam em falar de uma "sociedade de risco" (Beck, 2001), colocando assim a questão do desenvolvimento sustentável no centro das preocupações. $\mathrm{O}$ crescimento dos riscos revela os limites da racionalidade tecnocientífica e a necessidade de uma racionalidade social e ética, se quisermos que o futuro não seja moldado por cegos. Essa escalada dos riscos dá igualmente uma dimensão política a campos considerados apolíticos até algum tempo atrás, como é o caso do campo do meio ambiente. Assim, a modernização torna-se reflexiva, ou seja, objeto de reflexão e de questionamento (Giddens, 1994).

Segundo nossa terceira hipótese, a NSE participa de 
um novo paradigma, principalmente no que diz respeito ao lugar dos atores na mudança social, à fronteira entre ciência e valor, às relações entre o que se designa geralmente como economia e como social, bem como às regulações correspondentes. Diferentemente da sociologia econômica de cunho marxista dos anos 1960 e 1970, a NSE dá espaço aos atores sociais e individuais. Assim, a ruptura entre ciência e valor é questionada em nome da diversidade dos mundos (Boltanski e Thévenot, 1991) e dos repertórios, ou, ainda, das relações de força que presidem a produção do conhecimento científico (Callon, Lascoumes e Barthe, 2001). Nessa visão, as relações entre o econômico e o social são reconfiguradas, e seu conteúdo é redefinido. O econômico cessa de ser reduzido ao mercantil para incluir o não mercantil e o não monetário, na acepção de Polanyi, originando a expressão economia plural (Laville, 1994). O social, por sua vez, deixa de ser reduzido à distribuição e aos gastos sociais para tornar-se "capital social" (Putnam, 2001), um espaço de "investimento social". A segurança visa menos a impedir a mudança do que a promover a capacidade de enfrentá-la, daí a ênfase nas competências para conter a exclusão (Castel, 1995). Enfim, se a díade Estado-mercado havia relegado a sociedade civil ao segundo plano em favor da solidariedade abstrata da redistribuição realizada pelo Estado, as novas regulações e as novas formas de governança que lhes são associadas apóiam-se doravante na sociedade civil, no engajamento cidadão e nos stakeholders (Lévesque, 2005). Em seguida à forte valorização do Estado e do progresso técnico, emergem novos valores concernentes à qualidade de vida, à democracia e ao respeito ao meio ambiente. Em suma, a profundidade das transformações em curso seria tal que atualmente se pode falar de "uma transformação dos fundamentos da transformação" (Beck, 2001, p. 20).
Como quarta e última hipótese, supomos que a maioria das abordagens originadas da NSE, mesmo que bastante diversificadas entre si, sejam pertinentes para melhor repensar e compreender a economia como objeto sociológico. Assim, quisemos tirar vantagem de cada uma dessas abordagens em lugar de opô-las com o risco de banalizá-las ou de neutralizá-las. Resta agora a questão do método adotado para elaborar um panorama geral dessas abordagens. No caso da literatura anglo-americana, a tarefa seria mais fácil, pois dispomos de várias revisões de literatura relativamente exaustivas, como são os trabalhos de Martinelli e Smelser (1990), de Smelser e Swedberg (1994), e de Swedberg (2003, 1994). Entretanto, se nos limitássemos às obras de língua inglesa, assumiríamos que a NSE de língua francesa não existe; daí o interesse por uma pesquisa mais atenta a esta última.

\section{PANORAMA DAS ABORDAGENS DA NSE}

Para termos uma visão de conjunto da NSE que emerja desde o início dos anos 1980, concentramos nossa atenção nos estudos principais das diversas abordagens que se podem identificar a partir dos núcleos de produção (por exemplo, centros de pesquisa) e de difusão (revistas, editoras). Essas referências nos permitiram identificar uma dezena de novas abordagens (veja Quadro 1). Para cada uma delas adotamos uma grade visando caracterizar a sua definição de economia, os conceitos utilizados e os objetos estudados. Dessa pesquisa (Lévesque, Bourque e Forgues, 2001), consideramos aquilo que nos pareceu passível de contribuição para uma análise sociológica do desenvolvimento sustentável e adicionamos algumas contribuições mais recentes. Com base nessas premissas, numa pri-

Quadro 1 - Abordagens da NSE.

\section{LIINGUA FRANCESA}

MAUSS: contra o utilitarismo; paradigma da dádiva (Caillé e Godbout)

Economia social e solidária, economia plural (Laville e Roustang)

Regulacionistas: instituições e compromissos sociais, modelo de desenvolvimento (Aglietta, Boyer e Lipietz)

Economia da grandeza: mundos e cidades (Boltanski, Chapiello, Thévenot)

Economia das convenções: mundo da produção e mercado como organização (Favereau, Orléan, Salais)

\section{LÍNGUA INGLESA}

Nova Sociologia Econômica: redes e imersão social da economia (Granovetter)

Evolucionistas e neoschumpeterianos: sistemas sociais de inovação (Nelson, Winter, Dosi, Freeman)

Neocorporativistas: governança e democracia social (Schmitter e Streeck, Hollingsworth)

Novos institucionalistas: bifurcação e especialização flexível (Piore, Sabel, Hodgson)

Socioeconomia: nova disciplina e dupla dimensão da economia (Etzioni, Lawrence e Coughlin) 
meira seção revisamos a literatura de língua francesa, e, posteriormente, a de língua inglesa. Em ambos os casos, a ordem adotada reflete uma seqüência lógica e não uma ordem de importância relativa.

\section{Contribuições de língua francesa}

A abordagem do Movimento Anti-Utilitarista nas Ciências Sociais (MAUSS) vai mais além da inspiração no antropólogo Marcel Mauss, pois, em seguida a uma crítica ao utilitarismo, ela propõe um novo paradigma - o paradigma da dádiva - para interpretar a imersão social da economia. O esforço iniciado por Caillé (1988) nos conduz a uma crítica epistemológica da ciência econômica. O desdobramento dos trabalhos do MAUSS propõe uma reconstrução do objeto da economia partindo do paradigma da dádiva. Esta se torna, ao mesmo tempo, um elemento revelador da relação social e da troca mercantil, que é considerada posterior à dádiva, contrariando os diversos mitos defendidos pelos economistas. Se a troca mercantil libera as partes de qualquer dívida, a dádiva cria uma obrigação, como atesta o ciclo dádiva-contradádiva, ou melhor, dar-receber-ofertar. Nessa visão, nem a sociologia durkheimiana da obrigação, nem a teoria econômica do interesse conseguem interpretar a dádiva (Caillé, 1997). Segundo essa perspectiva, "não se deve tentar compreender a dádiva a partir dos princípios de funcionamento das esferas mercantil ou estatal, mas, ao contrário, tentar compreender essas esferas buscando aquilo que fundamenta a dádiva, partindo da própria dádiva" (Godbout, 2000, p. 8). Dito de outra forma, a dádiva como "fato social total" relaciona todos os elementos da sociedade: econômicos, políticos, religiosos, imaginários e familiares. Daí a idéia de um novo paradigma da dádiva para dar conta da inserção da economia na sociedade.

Se essa abordagem é pertinente para analisar as associações e, de forma mais ampla, um terceiro setor situado entre as redes baseadas em relações primárias e secundárias, pode-se perguntar se ela seria igualmente pertinente para analisar o Estado e o mercado. Os autores respondem positivamente, pois, segundo eles, a dádiva mostra bem como a relação das pessoas às coisas codifica as relações pessoais: é pelos objetos dados que se exprimem as relações pessoais. Ademais, se a sociabilidade da dádiva se diferencia das lógicas abstratas e anônimas do Estado e do mercado, ela se imiscui em seus interstícios e acaba por constituir o fundamento das sociedades modernas (Godbout, 1992, p. 265). Enfim, essa socioeconomia se inspira na idéia de que o valor da relação entre as pessoas determina a troca dos bens, permitindo pensar-se a economia como imersa na sociedade, mesmo que essa imersão seja acompanhada de diversas formas de dominação e de exploração, o que a análise também visa desvelar. Contrariamente à independência contextual defendida pela ciência econômica, essa socioeconomia dispõe-se a explicar os fenômenos econômicos relacionando-os aos seus fundamentos sociais, políticos, culturais e ambientais. Se a relação com a natureza não é claramente explicitada, a crítica ao utilitarismo, às pretensões da dádiva e ao seu papel nas relações sociais duráveis pode trazer uma nova luz para uma abordagem do desenvolvimento sustentável.

Caso queiramos falar de uma abordagem da economia solidária e plural, então devemos nos reportar a alguns sociólogos, como Laville, Eme e Roustang, que defendem uma espécie de recontextualização da nova economia social. Essa recontextualização desemboca em análises que vão além das iniciativas socioeconômicas em si: ela promove um questionamento da relação economia/sociedade (Perret e Roustang, 1993). A abordagem parte das análises de regulação da sociedade salarial dita fordista para questionar a finalidade das atividades econômicas, principalmente o fato de que o desemprego se faz acompanhar paradoxalmente por um crescimento das necessidades não satisfeitas. As iniciativas da economia solidária provêm de um engajamento cidadão que visa ampliar a democracia e promover a eqüidade. Como se pode perceber, os trabalhos dessa corrente trazem uma dupla contribuição: uma análise da relação economia/sociedade e uma análise das experiências empreendidas na economia solidária.

Diversamente dos economistas que definem a economia de um ponto de vista formal - "ciência que estuda o comportamento humano enquanto relações entre os fins e os raros meios de utilização alternativa" (Robbins, 1935) -, os autores da economia solidária definem a economia de um ponto de vista substantivo, como sugere Polanyi. Assim procedendo, o campo das práticas econômicas é ampliado para incluir não somente as atividades mercantis, mas igualmente as atividades não mercantis (a redistribuição) e não monetárias (a reciprocidade), atividades em que ocorre a produção ou a distribuição de um bem ou de um serviço. Entretanto, o lugar e o papel dessas diversas formas de atividade variam segundo o tipo de regulação prevalecente numa dada sociedade. Assim, a regulação keynesiana, que apostava na conjunção do Estado e do mercado, tinha por consequêencias a separação e a hierarquização das atividades, sempre relegando as atividades não monetárias (reciprocidade e dádiva) a um lugar e um papel residuais. Essa corrente propõe então uma economia plural para a sociedade e a pluralidade de atividades para os indivíduos. Tais propostas abrem espaço para a defesa de uma economia solidária, na qual o Estado é chamado 


\section{BENOîT LÉVESQUE}

não somente a reconhecê-la, mas também a apoiá-la.

Por outro lado, a análise das iniciativas geradas pela economia solidária permite ver como a associação de pessoas, combinada a um funcionamento democrático, facilita a hibridação de uma grande variedade de recursos. Os chamados novos serviços de proximidade concretizam a interiorização da oferta e da demanda por meio da construção conjunta pelos usuários e pelos profissionais afetados pela co-produção desses serviços. Se essa construção conjunta é observável nas iniciativas emergentes, ela supõe um funcionamento engendrado por uma democracia plural que se baseia não somente na representatividade, mas também na deliberação e numa governança apropriada (Lévesque, 2004). As experiências revelam a possibilidade de uma nova configuração das relações Estado-mercado-sociedade civil e um reimersão da economia no social e no político. Para tanto, um salto qualitativo se impõe, como atesta a proposta de um novo contrato social em escala nacional, européia e mundial. Enfim, a definição da economia social e solidária compartilha vários elementos com a definição do desenvolvimento sustentável, principalmente no que tange à eqüidade, à predominância das pessoas sobre o capital, ao domínio das comunidades sobre o seu próprio destino, etc. A internalização da oferta e da demanda pelas empresas, além de uma definição ampla da economia para incluir diversas formas de atividade, poderiam se revelar muito pertinentes para a construção de uma socioeconomia de desenvolvimento sustentável.

As duas abordagens seguintes, a da regulação e a das convenções, são fruto de estudos de economistas heterodoxos, ainda que diversos sociólogos utilizassem esses estudos e, em certos casos, lhes dessem uma versão sociológica (Bélanger e Lévesque, 1991). Esse aporte sociológico não passou despercebido aos olhos de Perret (2001, p. 11), para quem "a abordagem de regulação foi mais bem compreendida e utilizada por sociólogos e historiadores do que pelos economistas". Segundo algumas interpretações, tal abordagem surge no quadro do antigo paradigma da ciência econômica, distinguido-se deste, porém, em vários pontos, principalmente por uma explicação nova da crise e do papel das instituições.

Elaborado por Aglietta (1976) e popularizado por Boyer (1986), que foi reconhecido como o principal autor, a abordagem da regulação fornece uma explicação coerente tanto do sucesso da díade Estado-mercado como da sua decadência. Esse sucesso repousava sobre um compromisso patronal e sindical que promovia um alinhamento das normas de consumo às normas da produção em massa, por meio de diversas formas institucionais, inclusive da convenção coletiva e das políticas sociais. Esse modelo foi questionado por razões econômicas e políticas, como o esgotamento dos ganhos de produtividade, ocasionando a quebra do compromisso entre patronato e sindicato, seguido de novas demandas dos trabalhadores (por exemplo, demanda de autonomia e de participação). Além disso, o surgimento de novos atores (jovens, mulheres, ambientalistas, minorias culturais) deixa claros os limites do compromisso patronato/sindicato. A globalização também contribui para desfazer o ciclo virtuoso keynesiano: os aumentos de salários e de gastos sociais, em vez de gerar resultados desejados, representarão custos cujo peso será sentido tão fortemente quanto mais as economias nacionais se abrem ao mundo.

Do ponto de vista de uma sociologia econômica, a abordagem da regulação nos leva a considerar não somente as instituições em sua relação com a economia, mas igualmente a considerá-las como uma resultante de compromissos sociais entre atores coletivos, sob a égide do Estado e visando sua institucionalização. Se as relações sociais são assimétricas, o consentimento das diversas partes não deixa de ser necessário numa sociedade de direito, ao menos por duas razões: primeiro, pelo fato de que qualquer uma das partes não pode se impor independentemente da outra; segundo, a parte dominante tem necessidade da outra parte para o alcance de seus objetivos. Essa corrente propicia a compreensão da dimensão política da economia. As instituições cessam de representar uma realidade externa sobre a qual os atores sociais não teriam qualquer influência, todavia elas continuam marcadas pela ambivalência, já que constituem um espaço de limitações e também um espaço de aquisição de direitos. Sob esse ângulo de visão, o mercado é uma instituição que pode assumir uma forma moldada prioritariamente pela concorrência, como foi o caso no século XIX e no primeiro terço do século XX, mas também que pode ter uma forma administrada, como durante o período fordista (1945-1975). Desde então, a crise, que se inicia em 1975, é bem uma crise da díade Estado-mercado e não apenas do Estado.

Por outro lado, a corrente da regulação apresenta dois pontos fracos: ela tende, em sua maior parte, a limitar a sua análise ao território nacional, se bem que as últimas contribuições levam em consideração a globalização e a "financeirização", com o objetivo de identificar trajetórias nacionais (Boyer, 1999); ela confere centralidade às relações de trabalho, o que deixa pouco espaço às relações com os novos movimentos sociais, a exemplo do movimento ecológico. À exceção de Lipietz (1993), os partidários da regulação deram pouca atenção ao desenvolvimento 
sustentável, ainda que essa abordagem fornecesse uma definição do modelo de desenvolvimento.

Assim, o desenvolvimento seria realizado segundo as configurações nacionais comportando cinco elementos: i) um grande compromisso ou um contrato social entre as classes ou grupos sociais quanto aos grandes desafios a serem enfrentados pela sociedade; ii) um paradigma social no qual estejam claros os valores que circunscrevem os grandes desafios; iii) um regime de acumulação que dá certa estabilidade à partilha entre o que é relacionado ao investimento (lucro) e o que é relacionado ao consumo (salário), de um lado, e entre o investimento na produção e o incentivo ao consumo, de outro lado; iv) um modo de regulação sob a coordenação do Estado, sendo organizadas de forma coerente as diversas formas institucionais para assegurar a regulação tanto da produção como do consumo; v) uma inscrição na divisão internacional do trabalho entre os vários países. Essa definição suporia reordenações significativas para melhor lidar com a globalização e a reconfiguração do poder do Estado-nação. Ela permite conceber a profundidade das mudanças que exigiria um modelo de desenvolvimento sustentável, a começar por um novo contrato social, em seguida por um regime de acumulação "não produtivista" e um modo de regulação, levando em conta a interdependência entre o local e o global. Não obstante, o paradigma social emergente parece cada vez mais aberto ao desenvolvimento sustentável, engendrando assim um novo espaço de debates e de conflito (Beck, 2001).

Se a regulação elabora uma definição do mercado em termos de instituição, a economia da grandeza e a economia das convenções oferecem uma definição do mercado em termos de organização. A corrente da economia da grandeza, fortemente sociológica, e a corrente das convenções, sobretudo econômica, merecem ser distinguidas, mas no plano deste artigo elas são tratadas como próximas.

Boltanski e Thévenot (1991) demonstram como a crítica da ciência econômica pela sociologia de inspiração durkheimiana, ou inversamente, da sociologia pela ciência econômica apenas conseguiram banalizar ambas. Tal operação teórica apenas interpreta uma "cidade" - a mercantil - no caso da ciência econômica, por uma outra, a "cidade cívica", no caso da sociologia durkheimiana. A contribuição desses autores nos leva a acompanhar um esforço epistemológico para identificar os pressupostos desses "mundos" transformados em "cidades", ou seja, em mundos legítimos. Se esse esforço suscitar um entusiasmo bem mais expressivo, será necessário então reconhecer que a abordagem da economia das convenções (diferen- temente da economia da grandeza) não conseguiu ir mais além do que ser uma corrente disciplinar no âmbito da ciência econômica.

As cidades, tais como definidas pela economia da grandeza, em número de seis, constituem lógicas de ação ou de justificações legítimas para reduzir a incerteza no âmago das interações sociais. Elas foram formalizadas em estudos em que se podem facilmente identificá-las. Dessa maneira, temos A cidade de Deus, de Santo Agostinho, a cidade da inspiração que repousa sobre o princípio da graça; A política extraída das próprias palavras da Sagrada Escritura, de Bossuet, representa a cidade doméstica que reside na dependência pessoal; O leviatã, de Hobbes, como a cidade da opinião que se baseia na honra; uma Investigação sobre a natureza e as causas da riqueza das nações, de Adam Smith, exemplo da cidade mercantil que repousa no desejo de possuir bens raros; $O$ contrato social, de Rousseau, a cidade apoiada na atividade cívica que tem por base o bem comum; Da fisiologia social, de Saint-Simon, a cidade industrial que repousa sobre a eficácia. Mais recentemente, Boltanski e Chapiello (1999) propuseram uma sétima cidade emergente: a cidade do projeto, que daria uma legitimidade nova ao mundo da conexão ou das redes, evidenciado pela atual literatura administrativa. Numa perspectiva diacrônica, essa nova cidade corresponderia ao surgimento de um novo espírito do capitalismo, posterior ao capitalismo mercantil e ao capitalismo industrial.

Como afirma Dosse (1995), essa corrente constitui um dos pilares do pólo pragmático da nova configuração das ciências humanas na França. Se aceitarmos que esses seis ou sete mundos explicam a diversidade das lógicas de ação e as incertezas resultantes da ação dos atores, segue-se que a tipologia das cidades é útil para distinguir as diferenças que nascem no interior de um mundo, assim como os conflitos entre os diversos mundos: as diferenças podem ser eliminadas no interior de um mundo, enquanto os conflitos exigem um compromisso entre mundos, ou ainda o apelo a um bem superior a construir. A corrente da economia das convenções adicionará convenções específicas às exigências de coordenação próprias para a produção de bens e serviços. Daí as convenções de produtividade, de desemprego, de participação e de identidade para caracterizar as empresas e seu mundo de produção, além dos sistemas regionais e nacionais relacionados à produção (Salais e Storper, 1994). Comparados aos partidários da regulação centrados nas instituições, os convencionalistas elaboram uma teoria da organização na qual esta não é explicada como um substituto do mercado como fazem os institucionalistas. Mas onde o mercado é 


\section{BENOîT LÉVESQUE}

abordado como uma forma de organização entre outras, como uma criação social cuja legitimidade, quer dizer a constituição em "cidade", é relativamente recente.

Seria necessário, portanto, verificar como tais abordagens poderiam enriquecer uma socioeconomia do desenvolvimento sustentável e do ambiente, como também as consequêencias que representariam o surgimento de mundo da conexão e de uma cidade do projeto lhe conferindo legitimidade, estabelecendo assim um novo espaço de reivindicação. Sob essa perspectiva, Boltanski e Chapiello demonstram que os projetos incentivam claramente a proliferação de redes, porém ainda estão longe de ser intercambiáveis.

\section{Literatura de língua inglesa}

Granovetter (1985) é freqüentemente identificado como o principal autor da Nova Sociologia Econômica (Swedberg, 1994; 1987). Sua abordagem é baseada mais na crítica da concepção do indivíduo atomizado do que na crítica da racionalidade defendida pelos economistas. Nessa visão, sua análise se aproxima da economia da grandeza, uma vez que se distingue da sociologia durkheimiana e da ciência econômica neoclássica. Granovetter critica Polanyi por ter superestimado a imersão social da atividade econômica nas sociedades tradicionais e primitivas, e por ter subestimado essa imersão nas sociedades modernas, nas quais o autor considera que o mercado só funciona bem quando mobiliza redes. Para ele, a sociologia durkheimiana, a ciência econômica clássica e a neoclássica não têm sucesso ao tentarem conceber o indivíduo socialmente situado. No caso da sociologia, as preferências individuais desaparecem em favor da obrigação e da coerção que se exercem do exterior sobre os indivíduos. No caso da economia, os indivíduos deixam de existir como entes socialmente situados e diferenciados em favor de preferências fundadas unicamente na racionalidade formal.

Inspirado em Berger e Luckmann (1992) com a construção social dos mercados e em Harold C. White (1981) com as redes, Granovetter $(2000 ; 1990)$ estabelece três postulados para a análise da economia: toda ação econômica é uma ação social; a ação econômica é socialmente situada; e as instituições econômicas são construções sociais. Partindo desses postulados, o autor defende que a sociologia econômica deve reunir condições para fornecer uma explicação da economia alternativa àquela dada pelos economistas neoclássicos, principalmente os neoinstitucionalistas, os quais sustentam que as instituições se impõem pela sua eficiência e que são apenas substitutas para o mercado. Análises empíricas lhe permitem demonstrar como as tecnologias e as formas de propriedade impostas não resultam do cálculo de rentabilidade nem da superioridade da tecnologia escolhida, mas de redes nas quais os promotores estão inseridos, como revela a vitória de Edison no caso da eletricidade nos Estados Unidos. Da mesma forma, o sucesso dos chineses, se comparado com o de outras minorias nos Estados Unidos, pode ser explicado não apenas pela força dos laços mantidos entre eles, mas também pela sua capacidade de se "desconectarem". Dessa forma, as empresas que criaram se beneficiam do amparo das redes, mas sem serem forçadas a assumir sem restrições a sustentação de todos os aliados. Para vencer nos negócios, como para obter um emprego, as redes são indispensáveis, porém não são impermeáveis à ineficiência. Ademais, os laços fracos são freqüentemente mais determinantes que os laços fortes, pois criam condições para o estabelecimento de passarelas entre as redes afastadas, mais ricas em informações novas e variadas (Granovetter, 2000).

Para Granovetter, a Nova Sociologia Econômica não pode se contentar em interpretar as instituições e o contexto no qual evoluem as atividades econômicas, devendo explicar igualmente o que decorre do centro do processo econômico, ou seja, dos mercados e da moeda (Steiner, 1999). Ao explicar por que os empresários decidem fazer uma operação de compra no mercado (buy) para obter um bem necessário à sua produção, ou adquirir uma empresa (make) para obter esse mesmo bem, Granovetter elabora uma crítica à teoria dos custos de transação de Williamson (1981) e propõe uma explicação sociológica mais convincente. Na ausência de redes confiáveis que lhe forneçam o bem necessário, o empresário acha mais seguro produzir aquele bem. A eficácia das redes é igualmente ilustrada pela busca de emprego da parte dos indivíduos. Esses diversos estudos contribuem para estabelecer que a economia de mercado incrusta-se no social por meio de redes. A pertinência da explicação sociológica é reafirmada sempre quando a ciência econômica neoclássica pressupõe que a economia mobiliza apenas indivíduos atomizados.

As outras abordagens elaboradas no âmbito da NSE (da qual faz parte a New Economic Sociology) podem ser qualificadas de institucionalistas, desde que fiquem bem distintas entre si. Em primeiro lugar, os "neo-institucionalistas", que continuam as idéias dos antigos institucionalistas Veblen e Common (não confundir com os neo-institucionalistas, como Coase e Williamson). Em segundo lugar, os evolucionistas, inspirados em Schumpeter. Em terceiro lugar, os neocorporativistas, que fornecem uma tipologia muito pertinente das formas de governança. Além disso, é preciso situar num bloco à parte a socioeco- 
nomia que, por meio da SASE - Society for Advancement of Socio-Economics, reúne sob um mesmo título todos os institucionalistas considerados num sentido amplo, mais as correntes culturais e normativas. A seguir, apresentamos breves comentários sobre essas abordagens.

Os "neo-institucionalistas" não tentam integrar as instituições no paradigma neoclássico, mas questioná-lo e criticá-lo. Essa abordagem se baseia em três hipóteses: a economia não pode ser considerada, ainda que de forma analógica, como uma ciência; a força principal da evolução é a tecnologia, entendida como um processo que pode incluir todos os tipos de instrumentos (até mesmo a linguagem) e de comportamentos que a eles se agregam; a economia deve ser considerada de um ponto de vista substantivo e levando em conta a sua inserção nas sociedades e instituições bem definidas (Hodgson, 1988). Estas últimas compreendem tanto as regras e as codificações oriundas do Estado como também as preferências e os esquemas cognitivos gerados no seio da cultura.

As novas propostas dessa escola se afirmam particularmente no início dos anos 1980, com Piore e Sabel (1984). Seu livro The Second Industrial Divide representa, sem dúvida, uma das contribuições mais conhecidas dessa corrente. A análise da prosperidade do pós-guerra, baseada numa combinação da hierarquia estatal e do mercado, aproxima-se da explicação dada pelos partidários da regulação. Mas o livro acaba por evidenciar uma bifurcação em termos da organização do trabalho ocorrida nos anos 1980, a partir das transformações do mercado e do surgimento de novas tecnologias de produção. De uma parte, a saturação da demanda de certos produtos de massa combinada a uma nova demanda de qualidade e, de outra parte, uma tecnologia que permite uma nova geração de instrumentos polivalentes estabelecem, ambas, as bases para uma especialização flexível, tornando possível uma produção diversificada, uma requalificação do trabalho e novas formas de cooperação. Assim, operacionalizando novos arranjos institucionais, seria possível repensar a produção, apostando mais em redes de pequenas empresas bem enraizadas no território, e, sobretudo, abandonar uma forma de organização do trabalho que tem como fundamento o parcelamento das tarefas. Em suma, na síntese que alguns autores propõem do institucionalismo e do evolucionismo, Hodgson, Samuels e Tool (1994) pregam um diálogo com todas as outras abordagens que se opõem à ortodoxia neoclássica.

Os evolucionistas de inspiração schumpeteriana, que são parte dos institucionalistas considerados num sentido amplo, defendem a idéia de que a ciência econômica se inspira erroneamente num modelo mecanicista, enquan- to a biologia poderia ser mais apropriada para interpretar as transformações da economia (Dosi, 1991). Se os neoschumpeterianos se interessam principalmente pelas inovações, sofrem influência dos institucionalistas ao propor os conceitos de novo paradigma tecnológico e de sistemas sociais de inovação (Nelson e Winter, 1982; Freeman, 1991; Dosi, 1982; Lundvall, 1992). Os autores dessa corrente analisam a dinâmica econômica em termos de ciclo longo e de paradigma tecnológico no plano macro, sem renunciar, entretanto, a abrir a "caixa-preta" das empresas no plano micro para desvendar as rotinas, aprendizagens e inovações de agentes econômicos caracterizados pela sua racionalidade limitada. Porém, mesmo reconhecendo o processo seletivo do desenvolvimento tecnológico, os neoschumpeterianos dão ênfase à importância dos aspectos intencionais da mudança tecnológica. Trabalhando com a idéia de inovações radicais que provocam uma ruptura no paradigma produtivo, essa abordagem questiona a noção de eficácia das técnicas, que não se verificam eficazes senão dentro de um dado paradigma (Freeman, 1991). Nessa perspectiva, as instituições tanto podem favorecer como bloquear a difusão de inovações, de maneira que uma dada trajetória constitui rapidamente um caminho de dependência, levando ao primeiro plano a determinação das escolhas políticas. Assim, é possível ampliar essas análises para dar conta das inovações tecnológicas e também das inovações sociais, que constituem, por sua vez, as inovações organizacionais e institucionais.

Os neocorporativistas, que reúnem institucionalistas principalmente europeus (Streeck e Schmitter, 1985), evidenciam a governança como modalidade e coordenação das pessoas e das relações sociais formalizadas num conjunto de regras e de mecanismos. Além de uma tipologia de modos de governança econômica, eles ressaltam o potencial econômico dos bens coletivos ou dos bens públicos, que, mesmo que constituindo um custo, representam uma vantagem para uma economia nacional. Nessa visão, os fatores extra-econômicos ou fatores sociopolíticos são freqüentemente determinantes para a maior parte das atividades econômicas. O qualificativo "neocorporativo" advém do fato de que eles levam em consideração não somente os indivíduos, mas também os atores coletivos e os grupos de interesse presentes na democracia social, muitas vezes mobilizados para a construção de bens coletivos no contexto da articulação ou da parceria.

Quanto à governança, os neocorporativistas destacam quatro formas ou ordens que combinam um princípio e uma instituição: a concorrência dispersa e o mercado, a hierarquia e o Estado, a articulação organizacional e a associação, a solidariedade e a comunidade. Se a duas 
primeiras formas dizem respeito basicamente a indivíduos, as duas últimas pressupõem atores coletivos que emergem da sociedade civil. A distinção entre a forma comunitária e a forma associativa é particularmente pertinente, já que evita confundir as governanças tradicionais, que repousam sobre o pertencimento comunitário (por vezes não voluntário), com as governanças modernas, que residem na associação voluntária de pessoas. Nessa interpretação, a democracia social pode complementar a democracia representativa, na medida em que favorece a deliberação entre indivíduos que representam interesses coletivos para construir um bem comum, ou ainda um interesse geral que vá além dos interesses coletivos. Essas análises foram continuadas por Hollingsworth e Boyer (1997), que demonstraram que o mercado e a hierarquia são apenas duas modalidades de coordenação entre uma pluralidade de outras igualmente importantes, ressaltando o engajamento, a associação, as alianças, as redes, as comunidades, as parcerias, etc.

Não poderíamos concluir este breve levantamento sem mencionar a socioeconomia, promovida pelo sociólogo americano Etzioni (1988). Essa abordagem, que se propõe reunir todas as correntes que aqui relacionamos, se diferencia claramente da economia política na medida em que esta última sempre esteve freqüentemente ligada ao marxismo e, mesmo quando esse não é o caso, sempre se inclinou a redirecionar a economia à política. A socioeconomia, por sua vez, centra-se mais no social do que na política, afirmando que a economia é parte integrante da sociedade. Se nos ativermos à plataforma que serviu ao lançamento desse grupo, veremos que a socioeconomia visa desenvolver um paradigma que combina as variáveis e os conceitos próprios da ciência econômica com aqueles de outras ciências sociais e humanas.

Mesmo que se reconheça sua complementaridade com a ciência econômica neoclássica e a utilidade de seus trabalhos, a socioeconomia não deixa de defender a inserção da economia e do mercado na sociedade. Ela também reconhece a multiplicidade das lógicas de ação, colocando, desde o ponto de partida, que o cálculo dos próprios interesses é acompanhado de outras motivações muitas vezes mais fortes e que provêm da moral, da obrigação, da emoção, da confiança e dos laços sociais. Em resumo, essa abordagem responde em grande parte a uma forte demanda de ética nos negócios e, mais amplamente, na sociedade (Turcotte e Salmon, 2005; Capron, 2000). Se por um lado, por meio da SASE, essa corrente promoveu um novo espaço de debate, onde as preocupações sobre o desenvolvimento sustentável e o ambiente estão presentes, por outro lado, com ela corremos o risco de nos reintroduzir no ciclo da especialização que caracterizava a antiga sociologia econômica.

\section{CONCLUSÃO}

A NSE de língua francesa e a de língua inglesa, que se ignoram mais do que se reconhecem, apresentam certas especificidades principalmente no plano da atenção que dão ao Estado, ao mercado, às instituições e aos atores sociais. Todavia, ao se considerar a diversidade das abordagens nas duas tradições lingüísticas, é possível encontrar fortes semelhanças, por exemplo, entre os convencionalistas e a NSE americana, entre os partidários da regulação e os novos institucionalistas anglo-americanos, entre o MAUSS e a socioeconomia de Etzioni. Ademais, as condições de surgimento são praticamente idênticas nos dois casos, isto é, uma grande transformação que se afirma no início dos anos 1980 e que dá lugar a um novo paradigma, em que a economia aparece fortemente dependente do social, mesmo que nesse momento o neoliberalismo proponha a autoregulação mercantil.

Pode-se concluir desse panorama da NSE que, por meio de suas diversas correntes, ela busca demonstrar que a economia é social. A economia é social pelos seus inputs, sejam estes subvenções, bens coletivos e públicos, sistema social de inovação, engajamento de empregados para além do contrato de trabalho ou, ainda, coletividades locais que aportem capital social, dotações institucionais e dotações culturais. Ela o é também por outputs, que não são apenas bens e serviços produzidos, mas também exterioridades, tais como empregos, desenvolvimento de coletividades, relação com a natureza, qualidade de vida, etc. Além disso, a NSE acrescenta que a economia é social pelo fato de o mercado constituir tanto uma forma institucional e organizacional como uma construção social. Enfim, a coordenação das atividades econômicas e da circulação de bens diz respeito ao mercado, à hierarquia e a governanças baseadas num nível elevado de engajamento social, como é o caso das associações, das redes, das alianças, das comunidades e coletividades as mais diversas.

Então, se a economia é social de ponta a ponta, onde se situa o problema? Por que alguns falam de economia social e solidária e da necessidade de uma reviravolta em direção ao desenvolvimento sustentável? A resposta é simples. A economia capitalista, de acordo com a ciência econômica clássica, geralmente não reconhece a dimensão social da economia. Como tudo é aparentemente pago em seu justo valor, reconhecem-se apenas os acionistas aos quais é concedido o monopólio relativamente exclusivo 
das decisões e dos resultados (lucros). Daí, os preços refletirem somente uma parte do valor da produção e uma parte dos custos, de maneira que a contabilidade nacional é igualmente falsa (Lipietz, 1993, p. 26). Sob esse ângulo, há uma imersão social da economia, como demonstra Granovetter, mas essa imersão é instrumentalizada em favor de uma economia totalmente capitalista e submetida ao curto prazo, o que dá finalmente razão à Polanyi.

O reconhecimento da dimensão social da economia, como bem demonstra a economia social e solidária, pressupõe um funcionamento democrático. Com efeito, o social e o sustentável são multidimensionais e adquirem plenamente sentido a longo prazo (por meio de diversas gerações), de maneira que seu reconhecimento será sempre uma construção social complexa e difícil, uma construção suscetível de variar consideravelmente no tempo, segundo os grupos envolvidos e os paradigmas sociais predominantes. Se o balanço contábil das empresas é realizado segundo normas relativamente conhecidas, uma contabilidade socioeconômica exige um tipo de acordo entre as partes sobre o que se pode reconhecer num dado momento como valor social, inclusive os aspectos econômicos, sociais e ambientais, como propõe o desenvolvimento sustentável. Ainda que esse reconhecimento não possa ser decretado espontaneamente pelo Estado, ele é eminentemente político. Nessa mesma perspectiva, Capron (2000) afirma que um comportamento socialmente responsável deve ter o cuidado de:

[...] constituir contrapoderes, de deixar que se exprimam as expectativas das diversas partes envolvidas [...] de criar condições para que as diferentes lógicas (mais ou menos antagonistas) possam ser consideradas nas escolhas fundamentais, de maneira que o máximo de aspectos econômicos, sociais e ambientais sejam levados em conta. (CAPRON, 2000, p. 276).

Portanto, o que se denomina comumente economia social e solidária representa um amplo leque de experimentos no domínio da economia. Nesse contexto, busca-se reconhecer a dimensão social, dando prioridade às pessoas sobre o capital, à utilidade social e ao interesse coletivo sobre o interesse particular, e trabalhando com os valores da solidariedade, da cooperação, da ajuda mútua, da equidade e da justiça social. Assim procedendo, a economia social fornece alguns princípios e regras que poderiam estabelecer um ponto de partida para se pensar de forma realista o desenvolvimento sustentável e uma economia socialmente responsável. Desse modo, o reconhecimento do social, abrangendo entre outros aspectos a eqüidade, a qualidade de vida e a relação Norte-Sul promovida pelo desenvolvimento sustentável, pressupõe não somente uma transformação do conjunto do sistema de produção e consumo, mas também uma democratização da economia e das instâncias apropriadas de regulação.

Enfim, a NSE mostra bem explicitamente que a economia, tal como é concebida pelos economistas neoclássicos, é uma economia mutilada, que torna mais problemática as políticas ao priorizar apenas a redistribuição feita pelo Estado e a ajuda internacional para restabelecer o equilíbrio, a fortiori para pensar um desenvolvimento sustentável. A NSE põe em questão uma visão igualmente mutilada da dimensão política, que se prende à política institucionalizada para lidar com o engajamento cidadão e as iniciativas socioeconômicas da sociedade civil, o que amplia ainda mais o raio de ação de um neoliberalismo centrado na autoregulação mercantil. Com efeito, "desde que integremos as interações sociais, todos os tipos de ineficácia macroeconômica aparecem, devido ao descompasso entre os dados ligados às pessoas (justamente suas responsabilidades) e os dados 'objetivos' (agregados, variáveis globais) da política econômica” (Mahieu, 2000, p. 263). Nessa perspectiva, a NSE engaja-se num esforço ecológico que se preocupa menos em tomar o poder do Estado e mais em mudar os comportamentos cotidianos e realizar uma série de micro-rupturas, ou ainda "uma revolução molecular que jamais se completará" (Lipietz, 1993, p. 41).

\section{REFERÊNCIAS}

AGLIETTA, M. Régulation et crises du capitalisme: l'expérience des ÉtatsUnis. Paris: Calmann-Lévy, 1976.

BECK, U. La société du risque: sur la voie d'une autre modernité. Paris: Aubier, 2001

BÉLANGER, P. R.; LÉVESQUE, B. La théorie de la régulation, du rapport salarial au rapport de consommation. Un point de vue sociologique. Cahiers de Recherche Sociologique, n. 17, p. 17-52, 1991.

BERGER, P. L.; LUCKMANN, T. The Social Construction of Reality: A Theatrise in the Sociology of Knowledge. New York: Anchor Books, 1966

BOLTANSKI, L.; THÉVENOT, L. De la justification: les économies de la grandeur. Paris: Gallimard, 1991.

BOLTANSKI, L.; CHIAPELLO, E. Le nouvel esprit du capitalisme. Paris: Gallimard, 1999 


\section{BENOÎT LÉVESQUE}

BOYER, R. La politique à l'ère de la mondialisation et de la finance: le point sur quelques recherches régulationnistes. L’Année de la Régulation, v. 3, 1999.

BOYER, R. La théorie de la régulation: une analyse critique. Paris: La Découverte, 1986.

CAILLÉ, A. Don, association et solidarité. Revue Internationale de l'Économie Sociale, n. 265, p. 49-57, 1997.

CAILLÉ, A. La démission des clerc: la crise des sciences sociales et l'oubli du politique. Paris: La Découverte, 1993.

CAILLÉ, A. Critique de la raison utilitaire. Paris: La Découverte, 1988.

CALLON, M.; LASCOUMES, P.; BARTHE, Y. Agir dans un monde incertain: essai sur la démocratie technique. Paris: Seuil, 2001.

CAPRON, M. Vous avez dit éthique? Éthique et économie: l'impossible (re) mariage. Revue du MAUSS, semestrielle, n. 15, p. 271-277, 2000.

CASTEL, Robert. Les métamorphoses de la question sociale: une chronique du salariat. Paris: Fayard, 1995.

CUSIN, F; BENAMOUZIG, D. Économie et sociologie. Paris: PUF, 2004.

DOSI, G. Perspective on Evolutionary Theory. Science and Public Policy, v. 18, n. 6, p. 353-369, 1991.

DOSI, G. Technological paradigms and technological trajectories: a suggested interpretation of the determinants and directions of technical change. Research Policy, n. 11, p. 147-162, 1982.

DOSSE, F. L'empire du sens: l'humanisation des sciences humaines. Paris: La Découverte, 1995.

DRAPERI, J.-F. De nouvelles relations entre l'économie et la société? Revue Internationale de l'Économie Sociale, n. 275-276, p. 7-10, 2000.

EIGLIER, P.; LANGEARD, E. Servuction: le marketing des services. Paris: McGraw Hill, 1998.

ETZIONI, A. The Moral Dimension, Toward a New Economics. New York: The Free Press, 1988.

FREEMAN, C. Innovation, change of techno-economic paradigm and biological analogies in economics. Revue Économique, n. 2, mars, 1991.

GADREY, Jean. Services: la productivité en question. Paris: Desclée de Brouwer, 1996.

GIDDENS, A. Les conséquences de la modernité. Paris: L'Harmattan, 1994.

GISLAIN, J.-J.; STEINER, P. La sociologie économique 1890-1920. Paris: PUF, 1995.

GODBOUT, J. T. Le don, la dette et l'identité: homo donator vs homo oeconomicus. Montréal: Boréal, 2000.
GODBOUT, J. T.; Caillé, A. L'esprit du don. Paris: La Découverte, 1992.

GRANOVETTER, M. Le marché autrement: essais de Mark Granovetter. Paris, Desclée de Brouwer, 2000.

GRANOVETTER, M. The old and the new economic sociology: a history and a agenda. In: FRIEDLANG, R.; RICHARDSON, A. F. (Org.). Beyond the Marketplace: Rethinking Economy and Society. New York: Aldine de Gruyter, 1990, p. 89-112.

GRANOVETTER, M. Economic action and social structure: the problem of embeddedness. American Journal of Sociology, v. 91, n. 3, p. 481-510, 1985.

HODGSON, G. M. Economics and Institutions: A Manifesto for a Modern Institutional Economics. Philadelphia: University of Pennsylvania Press, 1988.

HODGSON, G.; SAMUELS, W. J.; TOOL, M. R. The Elgar Companion to Institutional and Evolutionary Economics. Aldershot: Edward Elgar, 2 tomes, 1994.

HOLLINGWORTH, J. R.; BOYER, Robert (Orgs.). Contemporary Capitalism: The Embeddedness of Institutions. Cambridge: Cambridge University Press, 1997.

LAVILLE, J.-L. (Org.). L'économie sociale, une perspective internationale. Paris: Desclée de Brouwer, 1994.

LÉVESQUE, B. Un nouveau paradigme de gouvernance: la relation autorité publique-marché-société civile pour la cohésion sociale/A new governance paradigm: public authorities-markets-civil society linkage for social cohesion. Les choix solidaires dans le marché: un apport vital à la cohésion sociale/Solidarity-Based Choices in the Market-Place: A Vital Contribution to Social Cohesion. Strasbourg: Édition du Conseil de l'Europe/Council of Europe Publishing (coll. Tendances de la Cohésion Sociale, n. 14/Trends in Social Cohesion, n. 14), p. 29-66/29-67, 2005.

LÉVESQUE, B. Les enjeux du développement et de la démocratie dans les pays du Nord: l'expérience du Québec. In: Fall, A.; Favreau, L.; Larose, G. (Orgs.) Le Sud... et le Nord dans la mondialisation: quelles alternatives? Québec: Presses de l'Université du Québec, 2004, p. 97-132.

LÉVESQUE, B.; BOURQUE, G.; FORGUES,É. La nouvelle sociologie économique: originalité et diversité des approches. Paris: Desclée de Brouwer, 2001.

LUNDVALL, B.-A. (Org.) National System of Innovation: Toward a Theory of Innovation and Interactive Learning. London: Pinter Pub, 1992.

PERRET, B.; ROUSTANG, G. L'économie contre la société: affronter la crise de l'intégration sociale et culturelle. Paris: Le Seuil, 1993.

LIPIETZ, A. Vert esperance: l'avenir de l'écologie politique. Paris: La Découverte, 1993.

MAHIEU, F. R. De la responsabilité des économistes et des agents économique. Pour une éthique de la personne en économie. Éthique et Économie. Limpossible (re) marrage. Revue du MAUSS, semestrielle, n. 15 , p. $257-267,2000$ 
MARTINELLI, A.; SMELSER, N. (Orgs.). Economy and Society: Overviews in Economic Sociology. London: Sage Publications, 1990.

NELSON, R.; WINTER, S. National Systems of Innovation: A Comparative Study. Oxford: University Press, 1982.

PERRET, B. Préface. In: LÉVESQUE, B.; BOURQUE, G.; FORGUES, É. La nouvelle sociologie économique: originalité et diversité des approches Paris: Desclée de Brouwer, 2001, p. 9-15.

PIORE, M. J.; SABEL, C. Les chemins de la prospérité: de la production de masse à la spécialisation souple. Paris: Hachette (Primeira edição em inglês: The Second Industrial Divide, 1984), 1989.

PUTNAM, R. D. Making Democracy Work: Civic Traditions in Modern Italy. Princeton: Princeton University Press, 1993.

ROBBINS, L. The Nature and Significance of Economic Science. London: Allen and Unwin, 1935.

SALAIS, R.; STORPER, M. Les mondes de production: enquête sur l'identité économique de la France. Paris: Éditions de l'École des Hautes Études en Sciences Sociales, 1993.

SCHMITTER, P. Interest systems and the consolidation of democracies. In: MARKS, A. (Org.). Reexaminimg Democracy. London: Sage Publications, p. 156-181, 1992.
SOUSA SANTOS, B. La globalisation contre-hégémonique et la réinvention de l'émancipation sociale. In: MERCURE, D. Une société-monde? Les dynamiques sociales de la mondialisation. Québec: Les Presses de l'Université Laval, 2001.

STEINER, P. La sociologie économique. Paris: La Découverte, 1999.

STREECK, W.; SCHMITTER, P. (Orgs.). Private Interest Government: Beyond Market and State. London: Sage Publications, 1985.

SWEDBERG, R. Principles of Economic Sociology. Princeton: Princeton University Press, 2005.

SWEDBERG, R. Une histoire de la sociologie économique. Paris: Desclée de Brouwer, 1994.

TURCOTTE, M.-F; SALMON, A. Responsabilité sociale et environnementale de l'entreprise. Québec: PUQ, 2005.

WHITE, H. C. Where do markets come from? American Journal of Sociology, v. 87, n. 3, p. $517-547,1981$.

WILLIAMSON, O. E. The economics of organization: the transaction cost approach. American Journal of Sociology, v. 87, p. 548-577, 1981.

ZIMMERMANN, J.-B. Entreprises et territoires: entre nomadisme et ancrage territorial. La Revue de l'IRES, Restructuration. Nouveaux Enjeux, número especial, n. 47, 2005/1, p. 21-35, 2005.

\section{Traduzido do francês por Maurício Serva.}

Artigo convidado. Aprovado em 26.02.2007.

\section{Benoît Lévesque}

Professor titular associado da ÉNAP - École Nationale d'Administration Publique e da UQAM - Université du Québec à Montréal. Presidente do Conselho Científico do CIRIEC International. Pesquisador titular do CRISES e da ARUC-ÉS.

Interesses de pesquisa nas áreas de economia social, inovações sociais, transformações sociais, desenvolvimento local e regional, trabalho e empresa.

E-mail: levesque.benoi@@uqam.ca

Endereço: Université du Québec à Montreal, Case postale 8888, succursale Centre-ville, Montréal (Québec), H3C 3P8, Canada. 